\title{
The Impacts of Presenting New Words in Semantically- Related Sets on Vocabulary Learning
}

\author{
Xingrong Wang \\ School of English, Tianjin Foreign Studies University \\ No. 117 MachangRoad, Hexi District, Tianjin 300204, China \\ E-mail: wangingod@163.com
}

Doi:10.7575/aiac.alls.v.6n.6p.111

Received: 03/07/2015

URL: http://dx.doi.org/10.7575/aiac.alls.v.6n.6p.111

Accepted: 08/09/2015

\begin{abstract}
This paper mainly explores the impacts of presenting new words in semantically-related (SR) sets on vocabulary learning. 38 students from two classes of Grade 2 in Taiyuan Foreign Language School (Senior High School Section) participate in the whole process. The same vocabulary items unknown to all students are taught to them in 4 lessons. The difference between the experimental group and control group is that words are taught in SR sets in the former and in the latter words belonging to the same SR sets are taught in different lessons. Independent Samples T-test is employed to see if there would be a significant difference between the two groups' performance in the English-Chinese translation tests of those words. The result shows that there doesn't exit a significant difference between the two groups in SHT test, but in the LT test two weeks later, SU group performs significantly better than SR group. The research findings may provide some enlightenment for foreign language researchers.
\end{abstract}

Keywords: Semantically-related (SR) sets, Senior high school students, Semantic field theory, Interference theory

\section{Introduction}

\subsection{Importance of the Problem}

Vocabulary learning is important in Second Language Acquisition (SLA). As the famous linguist Wilkins once said, "Without grammar, very little can be conveyed; without vocabulary, nothing can be conveyed" (1972, p. 111). Then there comes a question: As vocabulary learning is of such great importance, which way should teachers adopt to present vocabulary items so as to best benefit the learning?

Presenting vocabulary in SR sets could be seen in many EFL textbooks ( $\mathrm{Pu} \mathrm{2004,} \mathrm{p.} \mathrm{3).} \mathrm{Some} \mathrm{vocabulary} \mathrm{books} \mathrm{also}$ put words of a certain category together to facilitate memorizing (e.g. TOEFL Vocabulary Classified). Besides, many writers suggest teaching words in SR sets and have their justifications (Nation, 2000, p. 6).

Although many theorists and practitioners endorse this way of presenting vocabulary, there is not enough empirical evidence to support this position. In recent years, many researchers found that presenting vocabulary in SU sets led to the best outcome of students, while a minority of them found the contrary was better. However, some of these studies used artificial words rather than words from a natural second language. And some provided different words to the experimental and control groups. Besides, few studies in this area have taken senior high school students as subjects; therefore, in the present study, whose purpose is similar to the previous ones, 38 senior high school students were chosen as the subjects and the same new English words were presented to both groups in different manners.

\subsection{Theoretical Background}

Semantic field theory is based on an assumption that the vocabulary of a language consists of many interrelating networks of relations between words, not of a long random list of words. These interrelating networks are semantic fields (Channell, 1981, p. 117). It was psycholinguists who established the concept of semantic field (AlShaikhi, 2011, p. 17) and it was J. Trier, a German Scholar, who brought the semantic field theory to its puberty in the 1930s (Guo, 2010 , p. 51). According to Trier's theory, vocabulary in a language is semantically related and forms a complete lexical system, which changes constantly, so we should study the words as an integrated system, only in which a word is meaningful (cited in Wu, 1988, pp. 94-95). In Linguistics: A New Course Book, the relations between words could be divided into different categories: synonymy (e.g. answer-reply, deep-profound), antonymy (e.g. pass-fail, marriedsingle), homonymy (e.g. flour-flower, toe-tow), hyponymy (e.g. vegetable: potato, cabbage and carrot), meronymy (e.g. body: head, neck and leg) and etc. (Liu and Wen, 2006, pp. 120-126).

Interference theory puts forward a different opinion that presenting words in SR sets could not facilitate vocabulary learning process. The interference theory was formulated by McGeoch and McDonald. In their study, it was found that when students were presented with synonyms, they performed poorest (1931, p. 587). According to Robert Waring, this finding, along with others, led to the formation of "Interference Theory", which states that "when words are being learnt at the same time, but are too 'similar' or share too many common elements, then these words will interfere with each 
other thus impairing retention of them"(1997, pp. 261-262). The interference theory provides considerable explanation to the poor performance of the SR group in many studies.

\subsection{Related Studies}

The research on the impact of presenting new words in SR sets on SLA started with Tinkham. He presented related and unrelated artificial words to 20 nonnative adult advanced-level English speakers and found that the participants learnt unrelated words more quickly than related words (1993, pp. 371-380).

Waring in 1997 replicated Tinkham's study in 1993 and the result of his study was the same with Tinkham's (1997, pp. 262-263).

Finkbeiner and Nicol got the same result as the above two. In the study, they also used artificial words as the material for 47 undergraduates, but they presented the same 32 words from 4 categories for both groups. In SR group, related items were blocked into groups of eight, while in SU group, words were scrambled within a block. However, as the 32 items came from 4 categories, it is inevitable that words of the same category may appear in the same block. This situation also happened in Hashemi and Gowdasiaei's study (2003, pp. 369-383).

Instead of using artificial words, Papathanasiou in Greece used 120 English words with 60 related sets and 60 unrelated sets. The result showed that adult beginners performed significantly better in the SU vocabulary tests than in the related ones, while children of intermediate level showed no significant difference between them (2009, pp. 313-322).

The research by Hashemi and Gowdasiaei showed a very different result. 60 students ranging from 20 to 30 in two classes in Iran had been taught 100 words and expressions from 13 different lexical sets in different ways in four lessons, respectively. The breadth and depth of their knowledge of the words were tested before and after the instruction. The results showed that students in the SR group achieved better results than students in the SU group (2005, pp. 340-361).

While in China, there were only a few researches in this area and their conclusions all support that of Tinkham. One was conducted by $\mathrm{Pu}$, in which 100 students of the first year in junior high school were chosen as the subjects. 50 students were taught 20 SU sets and the others were taught 20 SR sets. Students' knowledge of the words were tested before and after the instruction (2004, pp. 30-41). Another was made by Zhang and Sheng. 80 university freshmen were taught 20 new words in SR sets and 20 new words in SU sets. Immediate and delayed tests were given after the instruction (2009, pp. 18-23).

From the review of the related studies, it can be found that in many studies concerning this topic, words for SR group and SU group are different. Some presented the same words to both groups, but in SU group the words of the same SR sets may appear in the same lesson.

\section{Research Design and Methodology}

\subsection{Research Question}

This study aims to address the following research question: Are there significant differences between presenting new words in SR sets and in SU sets to high school students in the SHT and LT tests?

\subsection{Sample Description}

55 students from two classes of Grade 2 in Taiyuan Foreign Language School (Senior High School Section) in Shanxi, China took the pretest and participated in the material collection part. However, only 38 of those participants attended all the sessions, obeyed all the instructions and remained to the last, with 19 in Class One as SR group (the experimental group) and 19 in Class Two as SU group (the control group). They have learnt English for 7 years and the English proficiency levels of the two groups, as defined by their mid-term English exam scores, were found to be roughly equal.

\subsection{Material Collection}

The paper test has two parts. The first part is about basic personal information--- class, sex, years of learning English and student ID number. In the second part, 105 English words are presented with a blank after each one. Students are required to put a " $\sqrt{ }$ " in the blank if they know its meaning. This part is designed in the purpose to collect the material for the study. All the words are GRE vocabulary, with at least one third of them appearing on a newspaper for senior high school students, namely Shanghai Students' Post. Besides, these words form 31 SR sets, which belong to five types of relationships---synonymy, hyponymy, homonymy, antonymy and meronymy. The words are presented sporadically on the paper. 60 words are expected to be collected as the final material for the study. The material must have two features. First, the material must be words that are unknown to all the students, to ensure that in the SHT and LT tests, if one writes down the meaning of a word, it is not from his/her previous storage of vocabulary, but is learnt from the instruction session. Second, in the material, there shouldn't be any single word which has lost its counterpart(s) in a SR set (see Appendix I.).

\subsection{SHT and LT Tests}

Both tests adopt L2-L1 translation, which is because Nation said it "has the advantages of being quick, simple, and easily understood" (cited in AlShaikhi, 2011, p. 48). One point is given to a student if he/she gives the right Chinese translation to an English word. The right translation is the translation which is taught in class. 


\subsection{Procedures}

The study was conducted during normal English class hours and their English teacher was present during all the treatment phase.

Four days before the treatment, students spent 25 minutes doing the papers for the material collection in class. It was found only 39 out of 105 words were unknown to all students. Among the 39 words, some lost their counterparts in the SR set, so some other words were added to make a total of 56 vocabulary items from 22 SR sets. The added words were tested before every lesson to make sure they were new to the subjects.

Four 20-minute lessons were given to each group to teach the 56 vocabulary items with about 14 per lesson. There was a two-or-three-day interval between two lessons. Before each lesson, the vocabulary items to be learnt in that lesson were written on the blackboard, along with their Chinese translation. For the added words, a star mark was written before it and students were asked whether they knew them. Among all the added words, "emolument" was known to one student, so the pair of antonyms containing it---"expenditure" and "emolument" was deleted from the total 22 SR sets, leaving 54 words as the final material. Of the 20 minutes, 15 minutes were used for teaching the new words. The instruction for both classes includes the pronunciation and the meaning of every word, and the sentences containing it. For the SR group, words belonging to the same SR sets were taught together in each lesson (see Appendix II.). For the SU group, words belonging to the same SR sets were taught in different lessons (see Appendix III.).

After the 15 minutes, students were given 2 minutes to review the words. Then the blackboard was cleaned, the SHT test papers were handed out and students were given three minutes to do the L2-L1 translation. After that, students handed in the papers, no matter they finished it or not. Two weeks after the instruction ended, the participants took the LT test with the same 54 items presented sporadically on the paper.

\section{Research Findings and Discussion}

\subsection{Data Analysis}

The data collection includes the data coming from the pretest (their mid-term exam), the SHT test and the LT test. The data for this study are analyzed by SPSS 17.0.

The pretest, which is actually their mid-term exam, was aimed to ensure the rough equality of the proficiency of the two groups. The total mark of the test paper is 150 .

Table 1. A Comparison of the Scores for the Pretest between SR Group and SU Group

\begin{tabular}{lllllll}
\hline & Group & $\mathrm{N}$ & Mean & Std. Deviation & $\mathrm{T}$ & Sig \\
\hline Pretest & 1 & 19 & 137.1579 & 5.38788 & 1.910 & .064 \\
& 2 & 19 & 133.8947 & 5.14128 & & \\
\hline
\end{tabular}

Table 1 shows that the mean score of SR group $(m=137.1579$, std=5.38788) and the mean score of SU group $(\mathrm{m}=133.8947, \mathrm{std}=5.14128)$ are not significantly different $(\mathrm{t}=1.910, \mathrm{p}=.064>.05)$.

Table 2. A Comparison of the Scores for the SHT Test between SR Group and SU Group

\begin{tabular}{llllllc}
\hline & Group & $\mathrm{N}$ & Mean & Std. Deviation & $\mathrm{T}$ & Sig \\
\hline SHT test & 1 & 19 & 48.6316 & 4.37430 & 1.478 & .148 \\
& 2 & 19 & 46.0526 & 6.22248 & & \\
\hline
\end{tabular}

The full scores for both the SHT and LT tests are 54. The results of the SHT test show that the mean score of SR group $(\mathrm{m}=48.6316$, $\mathrm{std}=4.37430)$ is higher than that of $\mathrm{SU}$ group $(\mathrm{m}=46.0526, \mathrm{std}=6.22248)$; however, no significant difference $(\mathrm{t}=1.478, \mathrm{p}=.148>.05)$ is found between the two groups.

Table 3. A Comparison of the Scores for the LT Test between SR Group and SU Group

\begin{tabular}{lllllll}
\hline & Group & $\mathrm{N}$ & Mean & Std. Deviation & $\mathrm{T}$ & Sig \\
\hline LT test & 1 & 19 & 14.2632 & 9.35618 & -2.381 & .023 \\
& 2 & 19 & 22.5789 & 12.00609 & & \\
\hline
\end{tabular}

The results of the LT test show that the mean score of SR group $(\mathrm{m}=14.2632, \mathrm{std}=9.35618)$ is lower than that of $\mathrm{SU}$ group $(\mathrm{m}=22.5789, \mathrm{std}=12.00609)$ and significant difference $(\mathrm{t}=-2.381, \mathrm{p}=.023<.05)$ is found between the two groups. 


\section{Discussion \& Conclusion}

The present study investigated the impacts of presenting new words in SR sets on vocabulary learning. The results showed that SR group performed better than SU group in the SHT test, but the difference was not significant. On the other hand, two weeks later, the results of the LT test showed SU group performed better than SR group and the difference was significant.

The above result suggests that presenting vocabulary in SU sets may assist the learning of new words better than in SR sets. This result is in agreement with those of previous researches by Tinkham's in 1993, Waring's in 1997 and Papathanasiou's in 2009, illustrating that presenting high school students with new words grouped in SR sets impedes rather than facilitates the process of learning. It should be mentioned that the result reinforces the positions of the researchers above since in this study the same new words from natural language were given to both groups in different manners, which previous studies lacked.

The result of the study also adds new testimony to the "interference theory", which believes less vocabulary gains are expected when the words are presented in SR sets. However, the result is not in line with the "semantic field theory", which claims that vocabulary teaching should make associations between SR words. Some guess when presented with new words, intermediate learners only need to add them to an existing storage, so presenting vocabulary in SR sets is best for them (Papathanasiou, 2009, p. 319); however, the finding of this study is against that assumption.

Though psychological researchers provide arguments that words in our brain are related in associative networks (cited in Hashemi and Gowdasiaei, 2005, p. 343), it does not necessarily mean presenting vocabulary items in SR sets facilitates the vocabulary learning process. In this study, presenting vocabulary in this way seems not beneficial to the learners.

Although SU group performed significantly better than SR group in the LT test, SR group performed a little better than SU group in the SHT test. The explanation for this is that in the SHT test with only about 14 words presented each time, there are some cases when words in the same semantic sets share a similar meaning with a nuance of difference, and students are not required to write the difference down, so the Chinese translations are the same for several words, thus elevating students' burden of memorizing. But this situation could only happen in the SHT test. When all the 54 words were presented together in a sporadic manner in the LT test, students in SR group face difficulty recognizing them.

\subsection{Recommendations for Further Study}

There is still much space left for further study. Firstly, there were 55 students from two classes at the beginning of the study, but at last, only 38 remained. The size of the sample is relatively small. If more subjects are involved, more reliable results might be achieved.

Secondly, because of the limited time for the study, the criterion for the choice of words is that the vocabulary items are unknown to all students; however, some words are not often used at an intermediate level. It might have influence on the result of the study. In further studies, the choice of the vocabulary items could be more compatible to the students' English level.

Thirdly, the form of the tests was only about to check students' grasp of the meanings of words, rather than their usages. Further study could measure the vocabulary depth of students' gains of target words in different ways, such as oral tests, sentence-making and so on.

It is hoped that this study could provide some enlightenment for foreign language researchers. Course designers could organize the words according to their normal use, rather than in contrived SR sets. Teachers might try different ways of presenting new words, such as presenting SR items at different times or in different contexts. Students might explore ways to avoid the interference when learning new words.

Acknowledgement: I give thanks to my mentor Ru Wang who gave me a lot of good advice in the whole process.

\section{References}

AlShaikhi, A. Z. (2011). The effects of semantic and thematic categorization of vocabulary on Arabic-speaking EFL learners. Colorado State University: Unpublished M.D. thesis.

Channell, J. (1981). Applying semantic theory to vocabulary teaching. ELT Journa, 35(2), 115-122. doi: 10.1093/elt/XXXV.2.115, http://dx.doi.org/10.1093/elt/XXXV.2.115.

Finkbeiner, M., \& Nicol, J. (2003). Semantic category effects in second language word learning. Applied Psycholinguistics, 24(3), 369-383. doi: 10.1017/S0142716403000195, http://dx.doi.org/10.1017/S0142716403000195.

Guo, Ch-H. (2010). The application of the semantic field theory in college English vocabulary instruction. Chinese Journal of Applied Linguistics, 33(4), 50-62.

Hashemi, M. R., \& Gowdasiaei, F. (2005). An attribute-treatment interaction study: Lexical-set versus semanticallyunrelated vocabulary instruction. RELC Journal, 36(3), 341-361. doi: 10.1177/0033688205060054, http://dx.doi.org/10.1177/0033688205060054. 
Liu, R-Q., \& Wen X. (2006). Linguistics: A new course book (pp.120-126). Beijing: Foreign Language Teaching and Research Press.

McGeoch, J. A., \& McDonald, W. T. (1931). Meaningful relation and retroactive inhibition. The American Journal of Psychology, 43, 579-588. doi: 10.2307/1415159, http://dx.doi.org/10.2307/1415159.

Nation, P. (2000). Learning vocabulary in lexical sets: Dangers and guidelines. TESOL Journal, 9(2), 6-10.

Papathanasiou, E. (2009). An investigation of two ways of presenting vocabulary. ELT Journal, 63(4), 313-322. doi: 10.1093/elt/ccp014, http://dx.doi.org/10.1093/elt/ccp014.

$\mathrm{Pu}, \mathrm{H}-\mathrm{Y}$. (2004). Effects of presenting new words in semantically related sets versus semantically unrelated sets on vocabulary acquisition. Northwest Normal University: Unpublished M.D. thesis.

Tinkham, T. (1993). The effect of semantic clustering on the learning of second language vocabulary. System, 21(3), 371-380. doi: 10.1016/0346-251X(93)90027-E, http://dx.doi.org/10.1016/0346-251X(93)90027-E.

Waring, R. (1997). The negative effects of learning words in semantic sets: A replication. System, 25(2), 261-274. doi: 10.1016/S0346-251X(97)00013-4, http://dx.doi.org/10.1016/S0346-251X(97)00013-4.

Wilkins, D. A. (1972). Linguistics in language teaching (p.111). Massachusetts: MIT Press.

Wu, Q-G. (1988). Introduction to semantics (pp.94-95). Changsha: Hunan Education Publishing House.

Zhang, L., \& Sheng, Y. (2009). A study of the influence of semantically-relatedness of word-sets on L2 vocabulary acquisition. Foreign Language Learning Theory and Practice, (4), 18-23.

\section{Appendix I. Material Collection}

第一部分 个人基本信息

1._班 2.性别:男○女○ 3.学习英语_年 4.学号

第二部分 单词测试

同学们, 该部分的设计是想了解你是否认识下列单词。这些单词是 GRE 词汇, 其中有些已出现在高中生的阅 读材料中。这些单词有一定难度, 你不认识没有关系, 这是正常现象。请同学们在自己确定认识的单词后面打 勾。(不认识或隐约记得但不确定的单词后请不要打勾)

\begin{tabular}{|c|c|c|c|c|}
\hline summon & wary & ubiquitous & linger & compensate \\
\hline capitalize & pledge & complement & distinctive & revenue \\
\hline mimic & blaze & evacuate & sophisticated & grieve \\
\hline dilemma & bicker & deference & hoax & fantasy \\
\hline predator & stalk & vulnerable & profile & robust \\
\hline hail & prompt & chameleon & indigenous & hull \\
\hline prototype & rampant & dissolve & circumspect & scant \\
\hline lag & atone & exert & violate & compliment \\
\hline prestigious & expenditure & simulate & tornado & regress \\
\hline naive & gloomy & bottleneck & squabble & adoration \\
\hline deception & utopia & prey & lurk & fragile \\
\hline guise & virile & hale & boost & badger \\
\hline petal & acquired & paradigm & pandemic & prudent \\
\hline sparse & postpone & offset & utilize & infamous \\
\hline tempest & withdraw & kernel & plight & wrangle \\
\hline contempt & delusion & mirage & facade & burly \\
\hline dwindle & clam & sprout & exotic & specimen \\
\hline prevalent & discreet & adjourn & supplement & notorious \\
\hline blizzard & quandary & dispute & affront & falsehood \\
\hline phantom & vigorous & configuration & impair & grouse \\
\hline pollen & drought & ostrich & sap & elate \\
\hline
\end{tabular}




\section{Appendix II. Treatment for SR Goup}

The First Lesson

I synonymy

wary 谨慎的在认为可能有危险或问题的情况下留神 Public are wary of GM foods

prudent 谨慎的 在金融、财务方面 a prudent investment

discreet 谨慎的在说话、办事上谨慎 a discreet protest

circumspect 谨慎的 carefully consider all circumstance to avoid error or unfavorable results

utopia 乌托邦 a society with perfect political and social system

hallucination 幻象 Was the figure real or just a hallucination?

II hyponymy 上下义

tempest 暴风雨/雪

avalanche 雪崩 an avalanche of papers 雪片般的试卷

III homonymy 同音异形异义

discreet 谨慎的

discrete 分离的、不相关的 a discrete random variable

IV antonymy 反义

dwindle 逐渐减少 dwindling consumer confidence

accrue 增加（esp. money or interest） Interest accrued to the company from loans.

gradable antonym 可分等级的反义词

affront 侮辱 be affronted by... an affront to sb.

disparage 轻视 look down upon

extol 颂扬 extol sb. to the skies

hallow 把...尊为神圣 Our Father in heaven, hallowed be your name. Halloween

The Second Lessson

I synonymy

sparse 稀少的 数量少、密度小 his sparse hair

scant 稀少的 数量少 the scant attendance at concert

stalk 悄悄地跟踪 A man stalked her and eventually killed her.

lurk 潜伏、暗藏 The snake lurks in the grass.

robust 强壮的、强劲的 Australia is known for high living standards and robust economy vigorous 强壮的、强劲的（与 robust 可以互换）

II homonymy

kernel 核 the peach kernel

colonel (空军、陆军)上校 Colonel Mitchell

III meronymy 整体部分关系

pollen 花粉

sap 树 (液); 活力 the sap of youth

stalk 茎

kernel 核 
IV blending of synonymy and antonymy (近义反义)混杂

evacuate 疏散 Nearly 3000 nearby residents were evacuated.

muster 召集 (军队) muster an army

convene 集合（商讨、开会）convene a summit meeting

The Third Lesson

I synonymy

bicker (为小事) 争吵 constantly

squabble (为小事) 争吵 noisily

wrangle 争吵 wrangle over sth./ with sb.

II hyponymy

ostrich 鸟鸟, 逃避现实的人

badger 獾, 纠缠 v. Dog packs constantly badger her about her private life.

grouse 松鸡, 抱怨 grouse about excessive taxation 抱怨苛捐杂税

fledgling (刚会飞的) 幼鸟, 初出茅庐的人 fledgling democracies 新兴的民主国家

III blending of synonymy and antonymy（近义反义）混杂

quandary 困境 George was in a quandary---should he go or not?

plight 苦境 the plight of the homeless

bottleneck 瓶颈 the bottleneck of production

weal 顺境 whether for weal or woe,...

The Fourth Lesson

I synonomy

guise 外表, 伪装 under the guise of

configuration 外形 fish of nondescript configuration

prevalent 普遍的 Sports are prevalent in America society.

rampant 猖獗的 rampant cheating

pandemic 流行的（病） a pandemic disease

offset 补偿, 抵消 The gains offset the loss 得失相当

compensate 补偿 The school apologized and the parents were compensated.

One can compensate insufficiency of knowledge with morals; while he cannot compensate moral deficiency with knowledge.

respite 缓期执行（死刑） respite a murderer

adjourn 休会 to stop a meeting or an official process, esp. a trial for a period of time

postpone 推迟 put off

II antonymy

fragile 易碎的、脆弱的 fragile emotion

stalwart 强壮的、结实的 a stalwart son

grieve 感到悲哀 It is too late to grieve when the chance is past

elate 使兴奋 His good grades elate his mom. elated 
Appendix III. Treatment for SU Group

The First Lesson

tempest

kernel

pandemic

hallow

configuration

The Second Lesson

affront

muster

fragile

accrue

pollen

The Third Lesson

disparage

stalk

grieve

avalanche

The Fourth Lesson

utopia

discreet

extol

squabble

colonel elate

prudent

quandary

wrangle

evacuate

guise

hallucination

plight

grouse

robust

ostrich

postpone

wary

weal

lurk

sap

fledgling

bottleneck

convene badger

adjourn

sparse

discrete

bicker

circumspect

scant

prevalent

offset

vigorous

dwindle

rampant

stalwart

respite

compensate 